knock on effects on antibiotic use and length of hospital stay, ways of preventing HAP would be of potential importance to health services.

\section{S14 TIME TRENDS AND RISK FACTORS FOR HOSPITALISATION AFTER COMMUNITY-ACQUIRED PNEUMONIA IN OLDER ADULTS IN ENGLAND}

ERC Millett, BL De Stavola, JK Quint, L Smeeth, SL Thomas. London School of Hygiene and Tropical Medicine, London, UK

\subsection{6/thoraxjnl-2014-206260.20}

Introduction and objectives Hospitalisation rates for community-acquired pneumonia (CAP) among older individuals have increased in Europe, but the reasons for this remain unclear. It may be due to increasing incidence of CAP in older adults, or an increasing tendency to hospitalise - either due to worsening comorbidities, and/or changes in service provision. We used English linked electronic health records to investigate trends in hospitalisation after a CAP diagnosis independent of CAP incidence, and determinants of any increasing trend.

Methods General practice records from the Clinical Practice Research Datalink (1998-2011) were linked to hospital admission records and mortality data, and CAP episodes among patients aged $\geq 65$ years were identified. Episodes resulting in hospitalisation within 28 days of CAP diagnosis were compared to non-hospitalised CAP episodes, and multilevel logistic regression models built to estimate odds ratios for co-morbidities, frailty, and other factors, and to predict the probability of hospitalisation over time. Indicators of CAP severity (including mortality in the 28 days post-CAP) and pathways of care were also examined as explanations for hospitalisation trends.

Results Hospitalisation after CAP increased markedly over the time period; after controlling for a wide range of comorbidities and other factors, the predicted probability of hospitalisation rose from 57\% (1998-2000) to 86\% (2009-2010). Factors associated with hospitalisation included 14 co-morbidities, five frailty factors, and four medications/vaccinations. In the fully adjusted model most of these factors were associated with increased odds of hospitalisation, but some (including dementia and terminal illness) lowered the odds of hospitalisation. Over the study period, a growing proportion of CAP patients were admitted to hospital via $\mathrm{A}$ and $\mathrm{E}$ and the proportion referred by general practitioners decreased. 28-day mortality decreased over time.

Conclusions Hospitalisation after CAP among those aged $\geq 65$ years has increased in England, independent of co-morbidity and frailty factors, while mortality has decreased. Changes in service provision, patient and physician behaviours may play a role in increasing CAP hospitalisations. If the incidence of CAP in this age group also continues to increase, these combined trends will place an expanding burden on the health service.

\section{S15 CLINICAL CHARACTERISTICS OF HOSPITALISED PATIENTS MISDIAGNOSED WITH COMMUNITY- ACQUIRED PNEUMONIA}

H Pick, J Lacey, D Hodgson, E MacDonald, A Turvey, T Bewick. Derby Hospitals NHS Foundation Trust, Derby, UK

10.1136/thoraxjnl-2014-206260.21

Background The diagnosis and treatment of patients hospitalised with community-acquired pneumonia (CAP) is predicated on an acutely abnormal chest radiograph. ${ }^{1}$ Little is known about patients who present with infective respiratory symptoms with no consolidation, who have clinically significant non-pneumonic lower respiratory tract infection (LRTI).

Methods A prospective observational cohort study of consecutive patients admitted to hospital with infective respiratory symptoms and treated for suspected CAP over winter 2013/14. Management was at the discretion of the admitting team.

Results Of 628 patients admitted to hospital during the study, $304(48.4 \%)$ did not have acute consolidation on chest radiograph; 166 were reported as clear, and 138 as either longstanding abnormality or not acute infection. Patients with LRTI had lower admission C-reactive protein levels (median $49 \mathrm{mg} / \mathrm{l}$ vs. 85 $\mathrm{mg} / \mathrm{l} ; \mathrm{p}<0.01$ ), were older (median 80.0 years vs. 76.3 years; $\mathrm{p}$ $=0.005)$, and were more likely to be managed on a non-respiratory ward $(174 / 304(57.2 \%)$ vs. $127 / 324(39.1 \%)$; p < 0.001). A higher proportion of patients with LRTI were care home residents, although this did not reach statistical significance $(56 / 304$ $(18.4 \%)$ vs. $45 / 324(13.9 \%) ; \mathrm{p}=0.12)$. A microbiological diagnosis was made in only 9/304 (3.0\%) patients with LRTI compared with 45/324 (13.9\%) with CAP $(\mathrm{p}<0.0001)$. CAP patients had a discharge clinical code of CAP (J12-18) in 247/ $324(76.2 \%)$ cases; 121/304 (39.8\%) patients with LRTI were miscoded as CAP. Thirty-day mortality was similar in both groups (48/324 (14.8\%) vs. 43/304 (14.1\%) p = 0.82), but median length of hospital stay was longer for patients with CAP (7.0 days vs. 5.6 days; $\mathrm{p}=0.002$ ).

Conclusion Almost half patients treated for CAP were misdiagnosed and over-treated with broad spectrum antibiotics. Patients with non-pneumonic LRTI were older, with lower C-reactive protein levels, but similar 30-day mortality. Acute respiratory illness in this group may therefore be driven by decompensated comorbidity rather than an underlying inflammatory condition; broad spectrum antibiotics may not be useful. No national guidance currently exists on the optimal management of this group, and further study is required.

\section{REFERENCE}

1 Lim WS et al. BTS guidelines for the management of community acquired pneumonia in adults: update 2009. Thorax 2009,64 Suppl 3,iii1-ii55

\section{S16 A RANDOMISED CONTROLLED TRIAL OF ATORVASTATIN AS A STABLE TREATMENT IN BRONCHIECTASIS}

${ }^{1} \mathrm{P}$ Mandal, ${ }^{2}$ J Chalmers, 'M Sidhu, 'D Davidson, 'A Rossi, ${ }^{3} \mathrm{~A}$ Hill. 'Queens Medical Research Institute, Edinburgh, UK; ${ }^{2}$ Tayside Respiratory Research Group, Dundee, UK; ${ }^{3}$ Royal Infirmary of Edinburgh

\subsection{6/thoraxjnl-2014-206260.22}

Background Bronchiectasis is characterised by chronic cough, sputum production, and recurrent chest infections. Pathogenesis is poorly understood, but excess neutrophilic airway inflammation is seen. Evidence suggests that statins have pleiotropic effects; therefore these drugs could be a potential anti-inflammatory treatment for patients with bronchiectasis. We did a proofof-concept randomised controlled trial to establish if atorvastatin could reduce cough in patients with bronchiectasis. In addition, we wanted to establish the anti-inflammatory mechanisms of statins contributing to this.

Methods Patients aged 18-79 years were recruited from the Royal Infirmary of Edinburgh. Participants had clinically significant bronchiectasis confirmed by chest CT and two or more chest infections in the preceding year. Individuals were randomly 


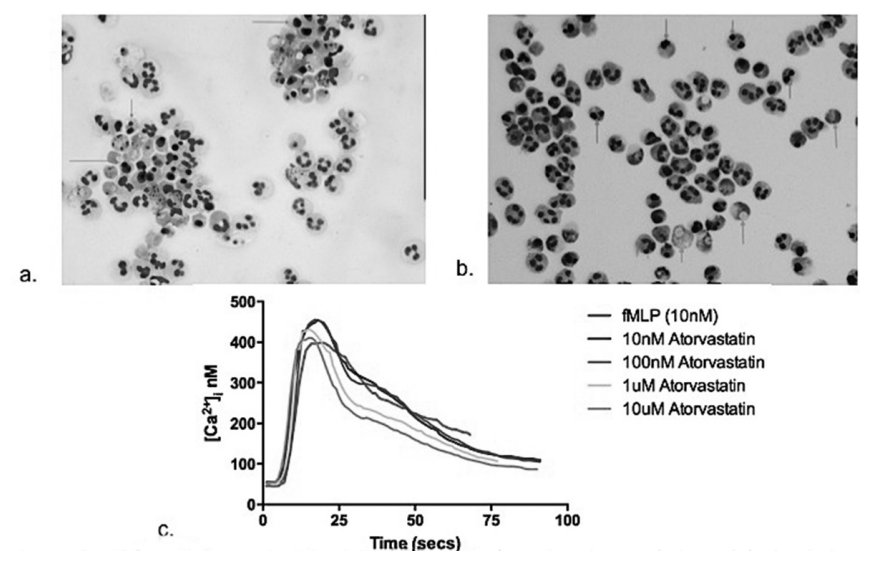

Abstract S16 Figure 1 Cytospin of control neutrophils at 20 hrs apoptosis; b. cytospin of atorvastatin treated neutrophils at $20 \mathrm{hrs}$ apoptosis; (red arrows indicate apoptotic neutrophils; blue arrows indicate 'ghost'cells) $\mathrm{C}$. dose response curve of fMLP induced increase in $\left[\mathrm{Ca}^{2+}\right] \mathrm{l}$ flux; reduced by Atorvastatin in a dose dependent manner. $\mathrm{fMLP}=$ formyl-Methionyl-Leucinyl-Phenylalanine

allocated to receive either atorvastatin $(80 \mathrm{mg})$ or a placebo, orally once a day for 6 months. Primary endpoint was reduction in cough from baseline to 6 months, measured by the Leicester Cough Questionnaire (LCQ) score (range 3-21; 3 severe cough; minimum clinically important difference, 1.3 units).

Findings (i) RCT 30 individuals were assigned atorvastatin and 30 were allocated placebo. There was evidence of a difference in baseline to 6-month change in LCQ between the treatment groups, with a significant improvement in the statin treated group, with a mean difference $2.2,95 \%$ CI for difference $(0.5$, 3.9) $\mathrm{p}=0.01$.

When analysed as proportion of improvement in LCQ, in the statin treated group $40 \%$ patients had a 1.3 Units or more improvement in the LCQ compared with $17 \%$ in the placebo group; difference in proportion 23\% (95\% CI for difference $1 \%, 45 \%), \mathrm{p}=0.04$.

There was significantly increased number of apoptotic airway neutrophils [mean difference of 8.9 (11.7); p = 0.04] with a trend towards a decreased total number of neutrophils in the sputum; $\mathrm{p}=0.09$; in statin treated group.

(ii) In vitro studies

Statins enhance apoptosis of neutrophils in vitro due to a reduction in stimuli induced increase in calcium flux.

Interpretation 6 months of atorvastatin improved cough on a quality-of-life scale in patients with bronchiectasis. Multicentre studies are now needed to assess whether long-term statin treatment can reduce exacerbations. Further studies are needed to establish if statins regulate $\mathrm{Ca}^{2+}$ flux by altering the intracellular or extracellular pathways.

\section{S17 CARDIOVASCULAR RISK FACTORS IN PEOPLE WITH BRONCHIECTASIS: A CROSS SECTIONAL STUDY}

${ }^{1} V$ Navaratnam, ${ }^{1} E$ Millett, ${ }^{2} J R$ Hurst, ${ }^{1} S L$ Thomas, ${ }^{1} L$ Smeeth, ${ }^{3}$ RB Hubbard, ${ }^{2}$ B Brown, ${ }^{1} \mathrm{JK}$ Quint. ${ }^{1}$ Faculty of Epidemiology and Population Health, London School of Hygiene and Tropical Medicine, UK, London, UK; ${ }^{2}$ Centre for Inflammation and Tissue Repair, University College London, London, UK; ${ }^{3}$ Division of Epidemiology and Public Health, University of Nottingham, Nottingham, UK

10.1136/thoraxjnl-2014-206260.23

\begin{tabular}{|c|c|c|c|c|c|}
\hline $\begin{array}{l}\text { Cardiovascular risk factor or prescription } \\
\text { of cardiovascular medication }\end{array}$ & & $\begin{array}{l}\text { Number of people } \\
(\%)(n=3,895,800)\end{array}$ & $\begin{array}{l}\text { Number without bronchiectasis } \\
(\%)(n=3,884,858)\end{array}$ & $\begin{array}{l}\text { Number with bronchiectasis } \\
(\%)(n=10,942)\end{array}$ & $\begin{array}{l}\text { Adjusted odds } \\
\text { ratio* }(95 \% \mathrm{Cl})\end{array}$ \\
\hline \multirow[t]{4}{*}{ Smoking status } & Never smoker & $773,094(19.8)$ & $768,975(19.8)$ & $4119(37.6)$ & 1.00 \\
\hline & Ex-smoker & $296,223(7.6)$ & $293,072(7.5)$ & $3151(28.8)$ & $1.30(1.23-1.36)$ \\
\hline & Current smoker & $605,205(15.5)$ & $601,533(15.5)$ & $3672(33.6)$ & $0.88(0.84-0.92)$ \\
\hline & Missing data & $2,221,278(57.0)$ & $2,221,278(57.2)$ & 0 & - \\
\hline \multirow[t]{2}{*}{ Hypertension } & No & $3,200,460(82.1)$ & $3,193,289(82.2)$ & $7171(65.5)$ & 1.00 \\
\hline & Yes & $695,340(17.9)$ & $691,569(17.8)$ & $3771(34.5)$ & $0.94(0.90-0.98)$ \\
\hline \multirow[t]{2}{*}{ Hypercholesterolemia } & No & $3,643,743(93.5)$ & $3,634,097(93.5)$ & $9646(88.2)$ & 1.00 \\
\hline & Yes & $252,057(6.5)$ & $250,761(6.5)$ & $1296(11.8)$ & $0.94(0.89-0.98)$ \\
\hline \multirow[t]{2}{*}{ Diabetes } & No & $3,708,873(95.2)$ & $3,698,882(95.2)$ & $9991(91.3)$ & 1.00 \\
\hline & Yes & $187,281(4.8)$ & $186,330(4.8)$ & $951(8.7)$ & $0.97(0.91-1.04)$ \\
\hline \multirow[t]{2}{*}{ Family history of cardiovascular disease } & No & $3,104,934(79.7)$ & $3,096,973(79.7)$ & $7961(92.8)$ & 1.00 \\
\hline & Yes & $790,866(20.3)$ & $787,885(20.3)$ & $2981(27.2)$ & $1.14(1.07-1.19)$ \\
\hline \multirow[t]{2}{*}{$\beta$ blockers } & No & $3,350,205(86.0)$ & $3,339,303(86.0)$ & $10,902(99.6)$ & 1.00 \\
\hline & Yes & $545,595(14.0)$ & $545,555(14.0)$ & $40(0.4)$ & $0.02(0 . .01-0.03)$ \\
\hline \multicolumn{6}{|l|}{ Angiotensin converting enzyme (ACE) inhibitor } \\
\hline \multirow[t]{2}{*}{ or Angiotensin II receptor blocker } & No & $3,448,012(88.5)$ & $3,437,161(88.5)$ & $10,860(99.3)$ & 1.00 \\
\hline & Yes & $447,770(11.5)$ & $447,697(11.5)$ & $82(0.8)$ & $0.03(0.02-0.04)$ \\
\hline \multirow[t]{2}{*}{ Nitrates } & No & $3,732,559(95.8)$ & $3,772,786(95.8)$ & $9773(89.3)$ & 1.00 \\
\hline & Yes & $163,241(4.2)$ & $162,072(4.2)$ & $1169(10.7)$ & $1.29(1.21-1.38)$ \\
\hline \multirow[t]{2}{*}{ Calcium channel blockers } & No & $3,572,373(91.7)$ & $3,563,365(91.7)$ & $9008(82.3)$ & 1.00 \\
\hline & Yes & $323,427(8.3)$ & $321,493(8.3)$ & $1934(17.7)$ & $1.02(0.97-1.08)$ \\
\hline \multirow[t]{2}{*}{ Anti-platelets } & No & $3,446,225(88.5)$ & $3,435,850(88.4)$ & $10,375(94.8)$ & 1.00 \\
\hline & Yes & $449,575(11.5)$ & $449,008(11.6)$ & $567(5.2)$ & $0.14(0.13-0.15)$ \\
\hline \multirow[t]{2}{*}{ Lipid lowering drugs } & No & $3,423,738(87.9)$ & $3,413,209(87.9)$ & $10,527(96.2)$ & 1.00 \\
\hline & Yes & $472,062(12.1)$ & $471,649(12.1)$ & $413(3.8)$ & $0.11(0.10-0.12)$ \\
\hline
\end{tabular}

${ }^{*}$ Odds ratios adjusted for age and sex 